\title{
MASS AND ENERGY BUDGETS OF ANIMALS: BEHAVIORAL AND ECOLOGICAL IMPLICATIONS
}

\author{
Progress Report
}

for Period May 1, 1991 - November 1, 1991

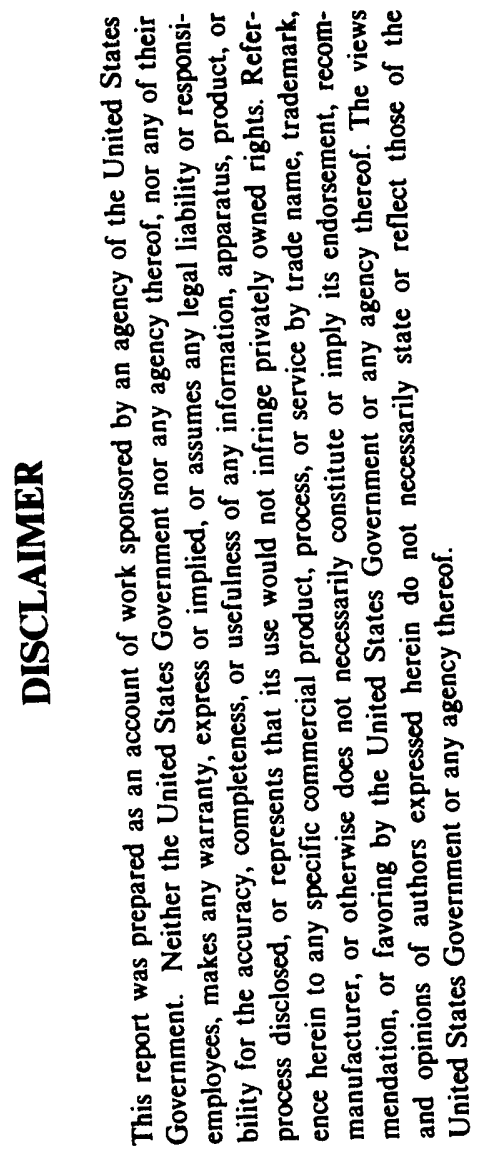

\author{
Warren P. Porter \\ Department of Zoology \\ University of Wisconsin at Madison \\ Madison, WI 53706
}

November 1991

Prepared for

THE U. S. DEPARTMENT OF ENERGY

AGREEMENT NO. DE-FG02-88ER60633.A007 


\section{Contents}

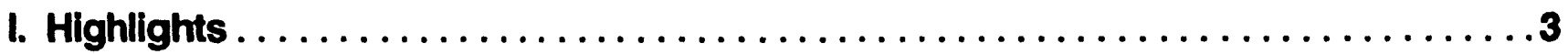

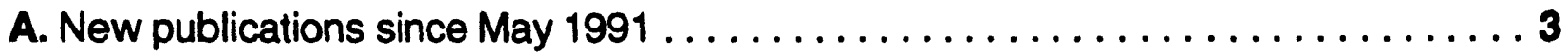

B. Changes in personnel and research directions $\ldots \ldots \ldots \ldots \ldots \ldots \ldots \ldots \ldots$

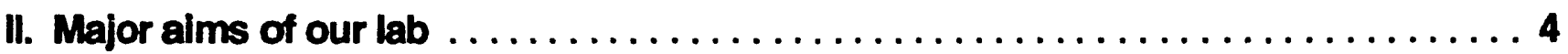

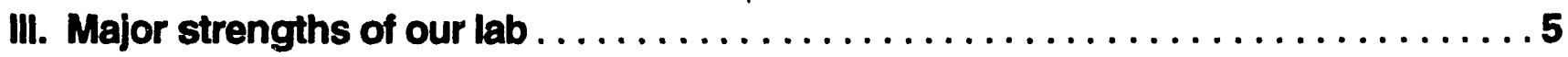

IV. Specific lab projects

A. A continental model for climate effects on growth and reproduction of selected ectotherms and endotherms $\ldots \ldots \ldots \ldots \ldots \ldots \ldots \ldots, \ldots \ldots \ldots$

B. Temperature and lizard life histories: physiologically based models . . . . . 88

C. A field irivestigation of microclimate constraints on time-energy budgets of beaver (Castor canadensis) in north-central Wisconsin . . . . . 15

D. An evaluation of physiological properties and demographic characteristics of the six-lined racerunner (Cnemidophorus sexlineatus) in southern Wisconsin . ........................23

E. An analysis of the effects of habitat fragmentation and climatic change on

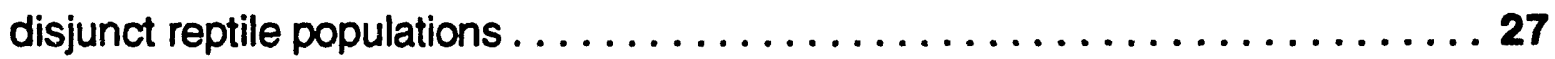

V. Appendix: Submitted manuscripts and publications supported by prior DOE awards 


\section{Highlights}

\section{A. New publications since May 1991}

Funding for our next three years officially began in May of 1991. Since then we have four publications accepted or in press. Four other papers have been submitted. Two of the four papers challenge conventional beliefs with new alternative hypotheses based on the models we have developed. These new publications are listed below, along with brief summaries. Submitted manuscripts are listed in the Appendix, along with five other recent publications funded by our prior DOE support.

1. Grant, B. W. and W. P. Porter. 1991. Modeling global macroclimatic constraints on ectotherm energy budgets. Physiological Zoology (in press). We use a mechanistic individual-based model incorporating macroclimatic and organismal properties to predict annual energy budgets and reproductive potential of the lizard Sceloporus undulatus. Predictions are in close agreement with results from previous field studies. This suggests that temperature, rather than food limitation, is the primary factor controlling potential population growth and reproduction in this species.

2. Carmi-Winkler, N., B. Pinshow, W. P. Porter and J. Jaeger. 1991. Water and energy limitations on flight duration in small migrating birds. The Auk (accepted). We examined the physiological limitations to flight duration in small migrating birds, using a computer simulation model incorporating temperature, altitude, humidity and physiological status of the birds. Contrary to accepted dogma, water, not energy, appears to limit flight duration, particularly in hot, dry environments.

3. Garland, T., Jr., and S. C. Adolph. 1991. Physiological differentiation of vertebrate populations. Annual Review of Ecology and Systematics 22: 193-228. We reviewed the literature on geographical variation (within species of vertebrates) in physiological traits. Although many studies report geographic differentiation, few have tested whether this differentiation is genetic or environmental. Thus, current data do not allow us to determine whether genetically based physiological adaptation is common or rare in vertebrates.

4. Reynolds, P. S. White blood cell profiles as a means of evaluating transmitter-implant surgery in small mammals. Journal of Mammalogy (in press). Surgically implanted radiotransmitters are sometimes used to obtain body temperatures of endotherms. However, surgery can lead to 
fever. This study showed that white blood cell counts can be used to detect infections that could affect body temperature measurements.

\section{B. Changes in personnel and research directions.}

Since we submitted our proposal last year, we have had some changes in personnel and research projects. New projects involve physiological models of temperature and lizard life histories (S. C. Adolph) and how habitat fragmentation and climate change interact to affect reptile populations (C. Curtin). Our project developing microclimate and physiologically based behavioral optimization models is delayed while Adria Cannon is on maternity leave.

\section{Major aims of our lab}

A. To develop and field-test general mechanistic models that predict animal life history characteristics (e.g., survival, age at first reproduction, and growth rate) as influenced by climate and the physical, physiological and behavioral characteristics of species. This involves several steps: (1) understanding how animal time and energy budgets are affected by climate and animal properties; (2) predicting growth and reproductive potential from time and energy budgets; (3) predicting mortality based on climate and time and energy budgets; and (4) linking these individual based models to population dynamics.

B. To conduct empirical studies of animal physiological ecology, particularly the effects of temperature on time and energy budgets. The physiological ecology of individual animals is the key link between the physical environment and population-level phenomena. (A and B are closely interrelated: field and laboratory data suggest changes in the models, and the models in turn suggest new directions for field and lab research.)

C. To make our models available to inexperienced users for basic and applied purposes. To this end, we have made substantial progress developing a user-friendly interface (using Microsoft Windows) that allows users to explore the interactions between an animal and its physical environment. A user can select an ectotherm, endotherm, or an inanimate object (e.g., a rock used as a shelter), specify its physical environment (e.g., air temperature, wind speed), and perform heat and mass balance calculations to determine body temperature, metabolism, and other physiological functions. This analysis can be performed in several different ways: (1) for a single combination of environmental variables; (2) for a range of values for two different environmental variables, to obtain a sensitivity analysis, and (3) for an entire year, using microclimate information produced as output from our microclimate model. In addition, our solar radiation and microclimate models are now being beta-tested by physiological ecologists at Idaho State University, the University 
of Idaho, and New Mexico State University. These programs run on both IBM compatibles and Apple Maclntosh machines.

\section{Major strengths of our lab}

Each person in our lab learns specific technical skills and conceptual approaches. These include: collecting microclimate data in the field; studying whole-organism physiology in the laboratory (e.g., metabolic rate); using computer models that relate microclimates to animal physiology and behavior; and how to combine the above skills to set up and analyze a particular research problem. By applying these tools, each person in our lab is then able to conduct research on:

1. how environments affect organisms, by applying first principles from meteorology and heat transfer physics.

2. how macroclimate affects the microclimates where organisms live.

3. how microclimates affect the physiology and behavior of individual organisms.

4. how physiology and behavior of individuals affect their growth, reproduction, and probability of surviving, which in turn determine populationlevel phenomena such as population size and geographic range.

The strengths of our lab are ideally suited to predict how climate change would affect animal populations. Although our empirical research is focused on mammals, birds, and reptiles, our modeling approach could readily be applied to other kinds of animals.

We have several research projects proceeding in parallel to address these questions for both ectotherms and endotherms in the field. Dr. Porter's part addresses the macroclimate to microclimate linkage on a broad spatial scale. Dr. Adolph's part addresses the links between individuals and population dynamics for lizard species. Ms. Reynold's work is a test of the endotherm energetics and behavior model using beaver. It will also be a test of the wet fur model that is nearing completion (under NSF support). Mr. Stein's work addresses the spatial variation in climate and its effects on individual energetics, growth and reproduction. Mr. Curtin's work addresses patchiness in the environment and constraints they may impose on individual energetics, growth and reproduction. These projects are described individually in the following section. 


\section{Specific lab projects}

\section{A. A continental model for climate effects on growth and reproduction of selected ectotherms and endotherms. Warren Porter}

\section{Specific aims.}

1. Implement the microclimate and animal models on a new HewlettPackard Apollo 720 workstation.

2. Transfer the databases (climate and geographic data) needed to drive the models to the new workstation.

3. Develop the computer code to run annual simulations for each of 250 sites on the North American continent for periods of up to 100 years.

4. Set up the input data format to be compatible with global clinnate simulation outputs from Dr. Kutzbach's Climate Change Research Center.

5. Perform initial calculations for (a) a lizard species with a broad geographic range (e.g., Sceloporus undulatus) and (b) the deer mouse, Peromyscus maniculatus, which has a continental distribution. We will compare their actual geographic distributions with computed feasible distributions.

Background and significance. Continental scale modeling of climate variation effects on animal population dynamics now appears feasible and reliable. We have recently completed two analyses that give us confidence in this approach. First, we have demonstrated the ability to accurately calculate reproductive potential across the distributional limits of a lizard species (Grant and Porter, 1991). Second, we have shown that correlations between survivorship and reproductive output in lizards can be explained on the basis of climate variation and lizard physical, physiological and behavioral properties, across wide variations in latitude and altitude (Adolph and Porter, 1991). These life history variables are traditionally used in population dynamics models. Establishing mechanistic links between climate variation and life history variables is a critical step in coupling macroclimate variation to population dynamics.

Progress Report. This is an entirely new direction. The workstation was ordered as soon as we received our funding in May, 1991. Available databases have been identified and placed on a borrowed SUN workstation. Further progress awaits delivery and installation of the new Hewlett-Packard 720 workstation.

The macroclimate-to-microclimate links have been tested at several different spatial and temporal scales (hundreds of meters over periods of up to ten years; hundreds of kilometers over more than a decade). We are beginning to extend the temporal and spatial scales to the North American continent for a span of 100 or more years. The workstation needed for this was ordered in May, but has not yet arrived. Nonetheless, the detabases needed for the 
simulations, i.e. plant distributions, topography, geology, precipitation and air temperature, have been assembled on another workstation for easy transfer once our machine arrives. Collaboration with Dr. John Kutzbach's Climate Change research group in Meteorology has been very helpful.

Links between microclimate and animal population dynamics are being tested through collaborations with several population biologists, Drs. Art Dunham and Karen Overall (University of Pennsylvania) and Dr. Byron Wilson (U.C. San Diego). Dunham and Overall have up to 17 years of demographic data on several populations of the lizard Sceloporus merriami in Big Bend National Park, Texas. Preliminary tests look very promising for predicting reproduction in different years. Dr. Wilson studied mortality in 7 populations of the lizard Uta stansburiana on the west coast. We are currently trying to determine whether these mortality rates are correlated with temperature and lizard activity (see Adolph's research report). In each case, we would like to know whether food availability or temperature (or a combination of both) is the best predictor of observed data. So far, climate seems to be the better predictor.

Finally, our collaboration with Dr. Warren Stewart in Chemical Engineering (funded by NSF) is yielding an excellent model of heat and water transport through fur. Theoretical predictions now agree very well with laboratory data. This is the last of the major individual models needed to simulate any kind of animal in any physical environment. The approach we used -- modeling fur as a porous medium -- could also be used to model heat transfer through bird feathers, and to model microclimates within grassland habitats.

Experimental Design and Methods. The most promising part of all this is that the approaches used in the more localized statewide or multi-state simulations (Grant and Porter; Adolph and Porter, ibid) are exactly the same as those we will use in developing a continental simulation. Namely, geological, topographic, and climate information from specific sites is used to reconstruct available microclimates through time. Microclimate model output drives the ectotherm model to compute discretionary mass and energy, which is converted to growth or egg production on a daily basis. The continental simulation will simply repeat this approach, but with 250 sites instead of a dozen or so. We will also be using a stochastic interface on the 'front end' of the microclimate model to compute percent available habitat through time to better estimate food consumption (Grant and Porter, ibid). We know food consumption is approximately a linear function of percent available habitat (a measure of microclimate availability) in at least one species of lizard (Grant and Porter, ibid). It seems reasonabie to use that assumption as a starting point for broader scale simulations. 
B. Temperature and Lizard Life Histories: Physiologically Based Models. Stephen C. Adolph, Postdoctoral Research Associate

Specific Aims. The broad goal of this research is to understand how temperature affects lizard life histories. We will develop and analyze mathematical models based on the temperature sensitivity of the physiological traits that underly life histories (e.g., metabolism and growth). Specific aims include predicting (1) the effects of temperature on energy budgets, and consequently on reproductive potential; (2) the effects of temperature on mortality; (3) how life history traits will covary phenotypically among different thermal environments; and (4) how life histories should evolve in different thermal environments.

Background and Significance. The extensive literature on life history theory presents a "top-down" approach: most models seek to predict the optimal reproductive strategy for a population experiencing a particular mortality schedule. Very few models have addressed life history features from the "bottom up" -- focusing on the physiological traits that underlie life histories. Top-down theories treat organisms as black boxes, whose responses to different environments are either unknowable or hypothetical. In contrast, bottom-up models are firmly founded on the known physiology of the organism: how growth rates respond to temperature and food availability, for example. Bottom-up models will help fill a large gap in our understanding of life histories: how they are expressed in different environments, and under changing conditions. In particular, these models will provide a tool for understanding how climate change (e.g., global warming) will affect life histories.

Lizard life histories are likely to be strongly influenced by temperature, both proximately and evolutionarily. However, few studies (empirical or theoretical) have examined this influence. This gap in our knowledge is peculiar, because temperature has long been recognized as a central factor in lizard ecology. Temperature affects lizard life history features in two general ways (Fig. 1). First, body temperature determines rates of physiological processes that govern the energy budget, including the energy that can be allocated towards reproduction. Second, environmental temperature limits the time a lizard can be active, both daily and seasonally. Activity times determine rates of energy acquisition and expenditure, and thereby ultimately limit the amount of energy that can be invested in reproduction. Activity times also affect survivorship, unless mortality risk is equal for active and inactive lizards.

Our models will link temperature and lizard life histories via thermal physiology. We foresee several important outcomes: (1) by linking thermal physiology and life histories, the model will unite two major areas of research on lizards; (2) the model will provide an alternative framework for interpreting patterns of life history variation, focusing on the role of environmentally induced 
variation; (3) physiologically realistic, individually based models will help address the complex problems of how life histories are expressed in difierent environments, how evolution might alter this pattern, and whether natural populations differ genetically in their responses to proximate effects.

Progress Report. We have analyzed a general mathematical model of the effect of the thermal environment on two lizard life history features, annual fecundity and annual adult survivorship. The model assumes that lizard activity is constrained by the thermal environment, so that daily activity times are short in spring and fall, long in summer. This annual activity pattern can be portrayed graphically as an ellipse, which is large for a warm environment and small for a cool environment (Fig. 2).

To examine the effect of activity time on life history features, we made simple assumptions about how daily activity time influences mortality risk and energy acquisition: (1) lizards have a constant risk of mortality during activity that is greater than their risk while inactive; (2) energy gain per day increases with hours of activity, but not necessarily proportionately; and (3) a constant fraction of this energy is allocated to reproduction throughout the active season. These assumptions are reasonable and are readily testable.

Given these assumptions, life histories will vary among populations in different thermal environments. Populations in warm environments will have higher annual fecundity, anci lower annual survivorship, than populations in cooler environments (Fig. 3). This pattern is purely phenotypic, representing the direct effects of temperature on individual lizards. Coincidentally, models of the evolution of life histories predict the same association between traits--a negative correlation between fecundity and survivorship--but for entirely different reasons. Thus, the proximate effects of temperature provide an alternative to evolutionary explanations. This result cautions against interpreting observed lizard life history patterns as adaptive, since they may not even represent genetic differences among populations.

Our model predicts that annual fecundity should vary positively, and annual survivorship negatively, with total annual activity time. We tested this prediction with life history data (gathered from the literature) on 11 populations of the widespread lizard Sceloporus undulatus. To calculate potential activity seasons for each population we used local climate data for the years of each field study. Climate data, coupled with lizard thermal properties and study site latitude and elevation, were used to solve heat balance equations on a microcomputer. These programs calculated the microclimates available to lizards at each site throughout the year, and determined the times (daily and seasonally) that lizards could be active at their preferred body temperature.

Populations with longer activity seasons had lower survivorship (Fig. 4a), supporting the predictions of our model for mortality. Results for fecundity were 
less definitive: annual fecundity (Fig. 4b) and annual egg mass (Fig. 4c) were positively correlated with activity season length, but the latter relationship was not statistically significant. Thus, activity season is a strong predictor of annual mortality, but a weaker predictor of annual reproductive output, in these populations of Sceloporus undulatus. These findings imply that temperature directly influences the life history phenotypes of this species, particularly their mortality.

Our theoretical results and empirical results suggest a simple prediction about how Sceloporus life histories would respond phenotypically to climate change. An increase in temperature would probably increase mortality and annual reproduction, provided that (1) activity time increases and (2) other parameters (e.g., hourly mortality risk, food availability) remain unchanged. Increases in both reproductive output and mortality would tend to compensate for one another.

These model results are included in a manuscript to be submitted to The American Naturalist. We will present this research at the 1991 meetings of the American Society of Zoologists, and will present current and future results in a symposium at the 1992 meeting of the Ecological Society of America.

Experimental Design and Methods. We will be working on several modeling projects during the next year of support. Each of these projects will involve a combination of mathematical analysis and computer modeling, and will be based on data from our prior research and from the literature. Where data are not available, we will use physiologically realistic models.

1. Effect of temperature on lizard digestion, energetics and growih. Gut function (e.g., digestive efficiency, food passage time) is temperature dependent. Because lizard body temperatures fluctuate daily, temperaturelimited digestion could be an important energetic bottleneck. We will use the chemical reactor approach to digestion developed by Penry and Jumars (1987, Am. Nat. 129:69-96). With this approach, the effects of temperature can easily be integrated. Our model will address several issues, including (a) how temperature and food availability interact to affect whole-animal energetics; (b) whether gut allometry and function can explain observed lizard growth patterns, such as size- and temperature-derendence; and (c) implications for foraging and therrnoregulatory strategies. We foresee a strong interaction between temperature and food availability: temperature increase is likely to be berieficial if food is abundant, but detrimental if food is limited. This prediction will be tested in our model.

2. Effect of temperature and activity on survivorship in the lizard $U_{\text {ta }}$ stansburiana. We have begun a project with Dr. Byron Wilson (Dept. of Biology, UC San Diego), who has measured survivorship in 7 populations of the lizard Uta stansburiana. These populations range from southern California to 
eastern Washington, and hence live in different thermal environments. We will determine whether activity time is correlated with mortality among these populations, as we have done for Sceloporus undulatus (see Progress Report above). Preliminary analysis suggests that temperature increases actually decrease mortality in Uta; in contrast to the increase we observed for Sceloporus. Thus, there may be no simple relationship between temperature and mortality, even for closely related lizards such as Uta and Sceloporus. This apparently contradictory result may be resolved by considering the effect of temperature on activity time; we will explore this issue further.

3. Lizard reproduction in a seasonal environment. Temperature limits annual growth rates, and consequently will affect life history features. We will model lizard growth in different thermal environments, to determine how temperature affects age and size at maturity. Given environmental effects on growth, we will then explore optimal reproductive strategies for different growing seasons. We will also examine the life-history consequences of food limitation, from both a proximate and an evolutionary standpoint. Our results will be compared to data on the lizard Sceloporus undulatus, whose life history is wellstudied.

4. Individually based model of lizard life histories. The aim of this model is to determine the joint effects of temperature, food availability, and individual variation on the distribution of life history traits in a lizard population. We will model growth and reproduction using physiological submodels, including those described above. The population will be heterogeneous: individuals will vary in their egg hatching dates, growth rates, etc. The model will keep track of individuals as they grow, mature, reproduce and die. We will explore how population size and age structure are affected by changes in thermal environments and resource abundance. Size and age structure are important determinants of population dynamics, because reproduction is size- and agedependent. Size and age structure also affect the evolution of life histories in a population. The model will focus on the lizards Sceloporus occidentalis and Sceloporus graciosus, for which we have extensive data on egg incubation, growth rates, fecundity, and the like. These lizards live in a variety of different thermal environments, so they are ideal for developing this model. 


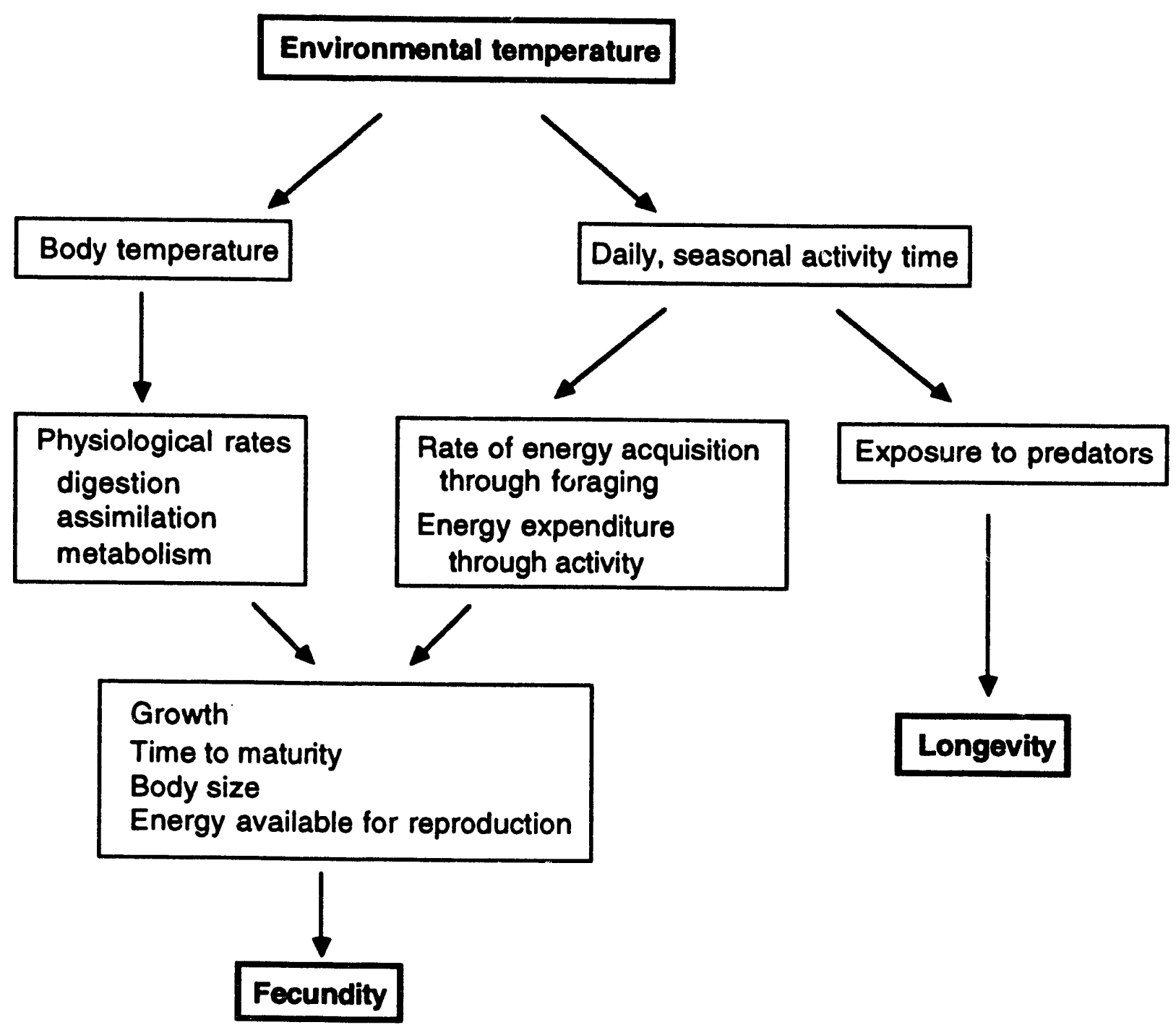

Figure 1. Mechanistic links between environmental temperatures and lizard life history features. 

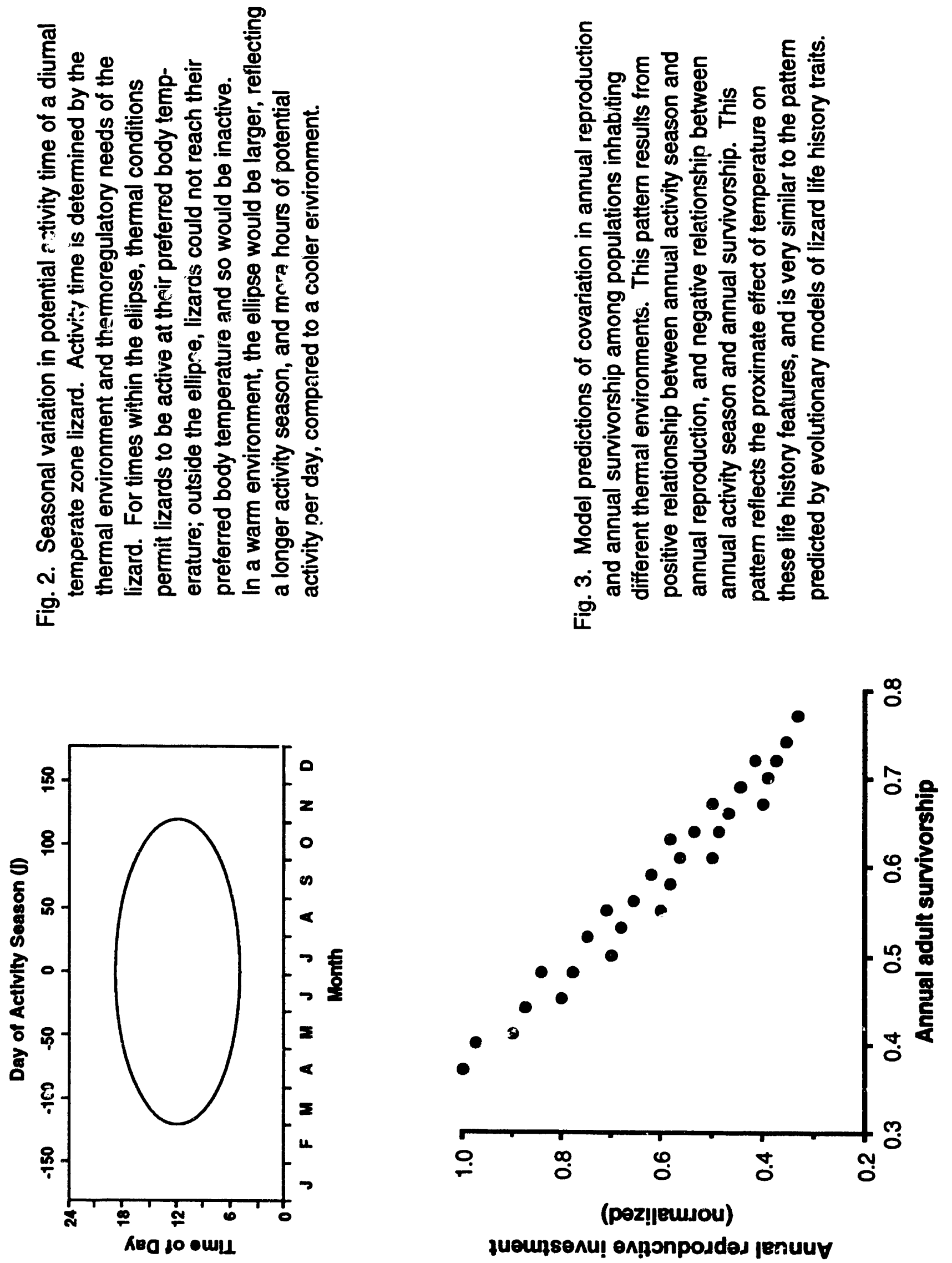

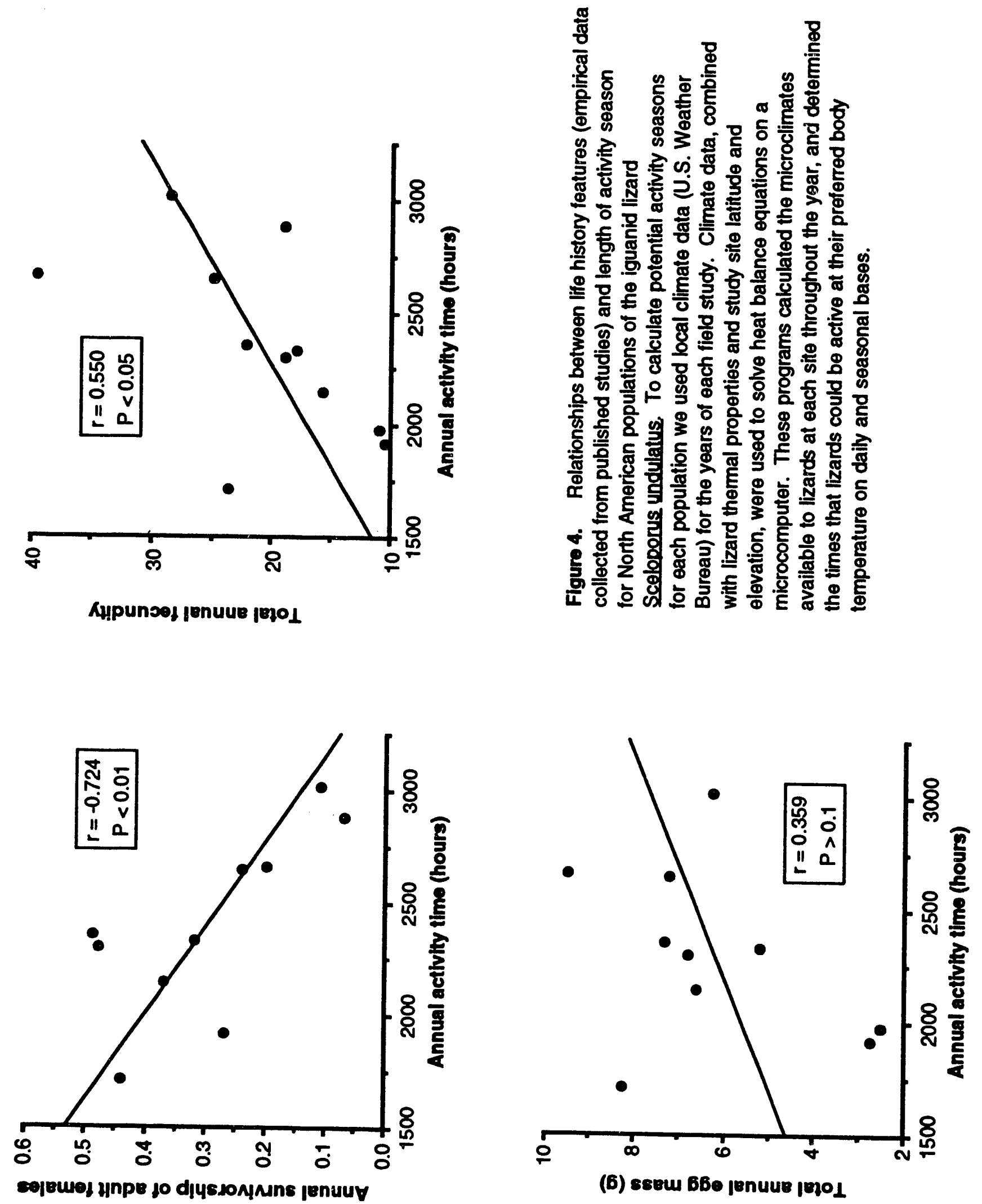


\section{A field investigation of microclimate constraints on time-energy budgets of beaver (Castor canadensis) in north-central Wisconsin. P.S.}

Reynolds, graduate research assistant

Specific Aims. The objective of this research is to determine the relative importance of microclimate parameters to time and energy budgets of beaver (Castor canadensis). Beaver spend a significant proportion of their activity time foraging; because this species is semi-aquatic, I predict that total foraging time is limited by how well individuals thermoregulate in water on both a daily and a seasonal basis. The interactive effects of microclimate variation and physiological response are ignored in many current models of animal foraging. In contrast, I predict that foraging patterns are influenced at least as much by microclimates as by the availability of food resources.

Major goals include:

1. predicting foraging patterns of beaver, a representative large generalized herbivore, in response to interactive effects of microclimate variation and resource abundance;

2. determining thermoregulatory patterns of free-ranging beaver over a period of one year. These data will clarify the possible role of body temperature depression and torpor as a means of reducing energy expenditures during periods of resource limitation;

3. determining thermal properties of beaver retreat sites. Rest-site selection is a critical determinant of maintenance energy costs.

4. statistical modeling of temporal variability in behavioral and physiological responses of individuals. The description and analysis of such time-series data requires the use of statistical techniques generally overlooked by ecologists. I show how existing time-series models may be applied to field measurements of body temperature data strings.

Background and significance. Although over-exploitation resulted in the nearextinction of beaver in the late 19th century, beaver populations have recovered much of their former geographic range and abundance, and beaver are now officially classified as a nuisance species in northern Wisconsin. However, the accelerating loss of wetlands once again threatens beaver, as well as other species dependent on this habitat. Understanding the interactions between microclimate and energy budgets at the individual level is critical for predicting how the key parameters of population change (individual survival, growth, and reproduction) will vary in response to changing environments. Further, it may be expected that microclimate variability, occurring on both a spatial and a temporal scale, will affect both the behavior and the physiology of an individual (Fig.5). The effects of temperature on various physiological traits of ectotherms are well-documented, but are less well-known for mammals in field situations. 
To this end, most of my research has centered on environment-organism interactions. Specifically, I examine the role of environmental variability occurring over different time scales (daily and seasonally) on selected performance criteria for individual beaver, including their use of time and space (behavior) and their thermoregulatory patterns (physiology).

Two hypotheses about beaver thermoregulation may be tested in a field situation. One aspect involves the potential effect of physiological constraint on short-term foraging decisions of an individual. I examine the hypothesis that (i) total foraging time and (ii) duration of foraging bouts of beaver may be limited by body temperature depression and hypothermia in response to acute cold challenge. This is based on the assumption that heat loss to water is a major energetic constraint for many aquatic mammals, and the observation that in some semi-aquatic species (e.g., mink and muskrat), foraging time is constrained by the decrease in body temperature that occurs when the animal is immersed in cold water. Over a longer time scale, I examine the effects of seasonal microclimate variation on thermoregulatory patterns over the yearly cycle; circumstantial evidence of other workers suggests beaver may reduce energetic expenditure in winter by metabolic depression and torpor. Alternatively, behavioral mechanisms, such as reduction of activity time and increasing time spent in the retreat, may serve to reduce energy costs, independently of thermoregulatory adjustment. If time spent in the retreat is of major importance, then rest site selection, competition between individuals for limited sites, and the tradeoffs inherent in retreat site selection (proximity to food, protection from predators, and thermal suitability) will impact foraging patterns to a greater extent than physiological adjustments.

\section{Progress report}

Statistical analysis of autocorrelated body temperature data. I have developed a statistical protocol for describing and analyzing body temperature profiles characterized by high correlation between observations. When correlation between observations in a body temperature series is ignored, the estimated standard errors will be biased downwards, thus giving false estimates of thermoregulatory precision. Subsequent statistical tests utilizing these biased standard error estimates will be invalid. However, autocorrelation can be accounted for by fitting an ordinary least-squares regression model to a body temperature data string, while simultaneously modelling the error term as a loworder Box-Jenkins time series process. In the simplest case, time is represented as an independent variable consisting of a vector of discrete, sequential time periods. A linear transfer term is incorporated for describing and analyzing "plateau" temperature patterns characterized by a distinct shift between resting and active body temperatures; in this case, time is represented by a dummy variable string with the values 0 and 1 . This method permits quantitative estimates of both the body temperature shift (difference between 
resting and active body temperatures) and the time constant (the time to achieve $63.2 \%$ of the new equilibrium). I have applied this method to body temperature patterns of beaver (Fig. 6); these results are included in a manuscript submitted to Ecology.

Thermorequlation in beaver. The assumption that semi-aquatic mammals are inefficient thermoregulators does not appear to hold for beaver. I found no evidence of hypothermia or torpor; beaver resting body temperatures did not vary with season, and active temperatures did not rapidly decline to a threshold low (as observed for muskrat). Body temperatures varied by approximately $1.5^{\circ}$ $C$ between active and resting periods; the time constant was relatively long (approximately 45-60 min). Beaver appear to depend on behavioral, rather than physiological, adjustments to minimize energy costs. Beaver showed major shifts in the proportion of time spent out of the retreat site (burrow or lodge; Fig. 7). The type of retreat site available affected maintenance costs of individuals, because lodges are more thermally stable than burrows. Limited field data suggested that colony members frequently competed for access to the main lodge during freeze-up, but that competition was not important during icefree periods.

I have also explored the thermal implications of size and shape in beaver and other aquatic and semi-aquatic mammals. It has been argued that enlarged propulsive appendages (tails and flippers) of aquatic and semiaquatic mammals result in larger surface area-to-volume ratios (compared to terrestrial mammals), which leads to greater heat loss and hence thermal inefficiency. To test this hypothesis, I collected data from the literature and from 20 individual beaver, and found that aquatic mammals do not have significantly greater surface area relative to terrestrial mammals. In fact, beaver have significantly lower surface areas than predicted for terrestrial mammals of their size (Fig.8).

Experimental Design and Methods. I studied beaver at Sandhill Wildlife Demonstration Unit, Wood Co., WI, courtesy of the Wisconsin Department of Natural Resources. Beaver were live-trapped and surgically implanted with temperature-sensitive radiotransmitters (Model S4, Telonics, Mesa, AZ). Body temperatures were recorded at $10 \mathrm{~min}$ intervals for $24 \mathrm{~h}$ once a month; rest site locations and corresponding body temperatures were determined weekly. I measured standard microclimate variables (wind speed, air temperature, water temperature, soil temperature, and insolation) concurrently. To determine empirically the thermal consequences of retreat site selection, I made additional microclimate measurements for two categories of retreat site (lodge and burrow) in two microclimate categories (full sun and shade). Morphometric data are obtained from carcasses obtained from trappers. 
The large body size and home ranges of beaver make manipulative work difficult in a field situation. Consequently, I rely on model-generated expectations of beaver time and energy allocation to compare with empirical data. Currently, I am working on three modeling projects, which will test different components of beaver allocation strategies.

1. An insulation-based model of thermoregulation, developed by Porter and McClure, quantifies the effect of microclimate on individual short-term performance (foraging time, habitat use), as mediated through selected physiological and morphological traits of the individual organism (body temperature, body size, fur). Because body temperatures of beaver vary by less than $2^{\circ} \mathrm{C}$ between active and resting phases, and fur is extremely dense, overheating may contsrain terrestrial foraging activity. The model will enable us to (i) predict the time course of postulated over-heating events and (ii) link terrestrial foraging time with ambient weather conditions. I have used a modification of this model to examine the trade-off between body size and insulation in a terrestrial arctic rodent (the collared lemming Dicrostonyx groenlandicus).

2. The second model estimates chamber temperature inside a beaver retreat, based on soil properties, ambient temperatures (soil, water and air), wind speeds, and insolation. Sub-adult beaver show little retreat-site fidelity in summer. In winter, proximity to food cached by the colony seems to be the predominant influence on site selection, overriding thermal considerations. Calculation of expected thermal properties for different types of retreat sites allows quantitative assessment of the tradeoffs involved in thermal- versus foodbased decision.

3. The third model incorporates microclimate effects into descriptions of optimal time allocation along a foraging path. The original model, developed by Arditi and Daracogna (1989; Am. Nat.) shows stepwise termination of a foraging bout as a function of food density; it has been shown to be a general case of Charnov's marginal-value theorem for patch choice. I tested the model with observations on beaver foraging on the aquatic plant Brasenia schreiberi. My observations supported the qualitative predictions of the model, both within a foraging session and over a season. However, quantitative responses were extremely variable. Local weather conditions, especially wind, appeare's to play an important role in both spatial and temporal responses of individuals; further work is required to incorporate abiotic factors into the model. 
Organism "filter"

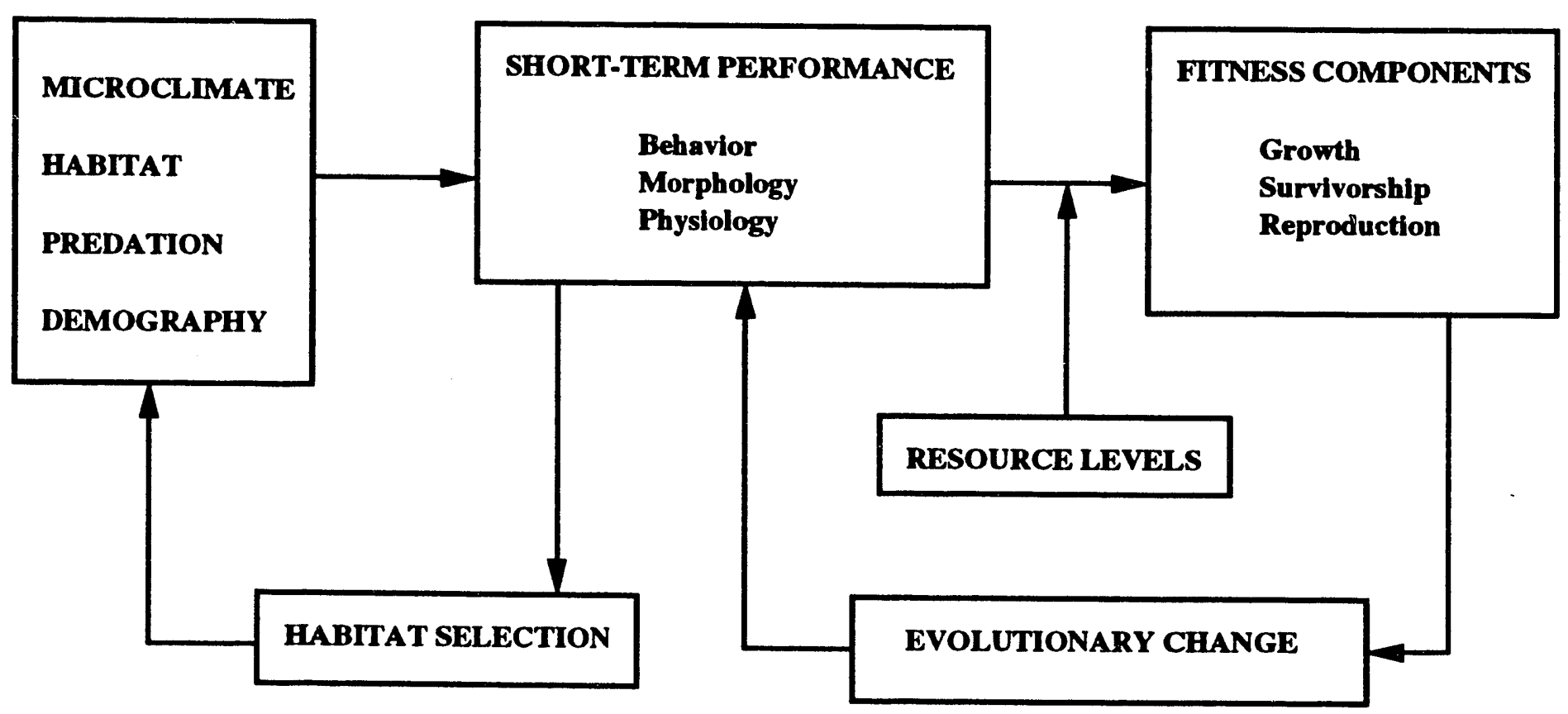

Fig. 5. Schematic showing the relationship between the environment, the organism and fitness components (adapted from Huey, 1990). The central concept is that properties of the individual organism act as a "filter" by which environmental variation is transduced to fitness. There are four major environmental components: predation, demography, microclimate and habitat. Predominant factors in the beaver system under study are habitat structure and microclimate. Empirical aspects of short-term performance of incividuals considered in this field investigation are (1) thermoregulatory patterns (physiology), and (2) foraging time allocation (behavior). The influence of major feedback links (e.g. habitat selection as it mediates environment-individual interactions) are examined by mathematical modeling. 
A.

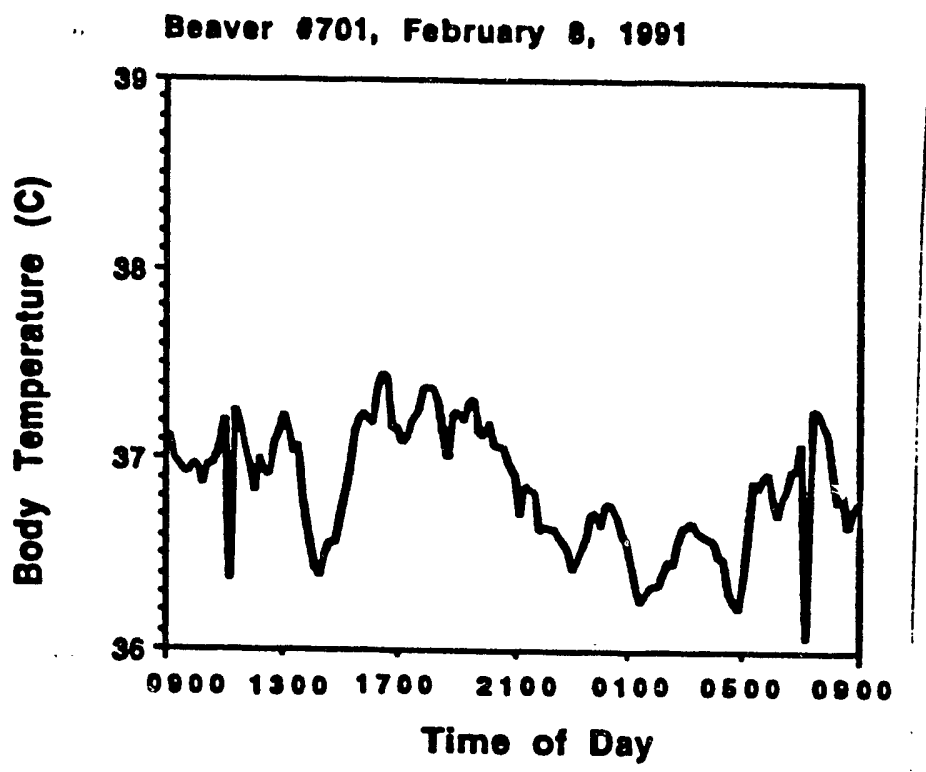

B.

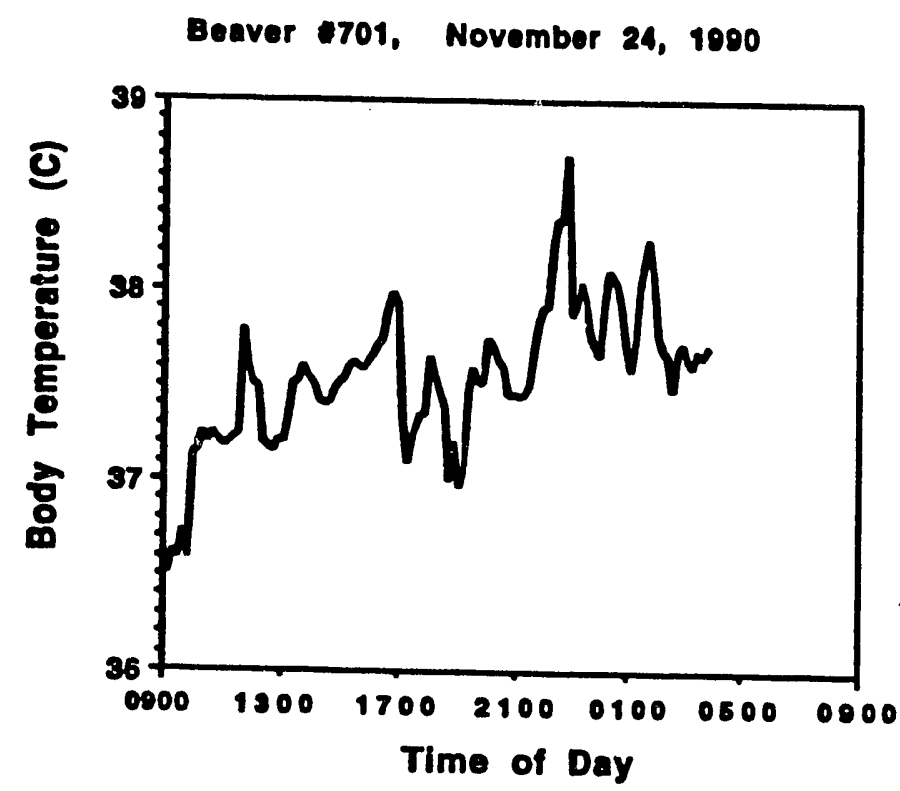

Fig. 6. Body temperature patterns of beaver during (A) freezeup (no trend), (B) freezeup (positive time trend) and $(C)$ ice-free seasons. 


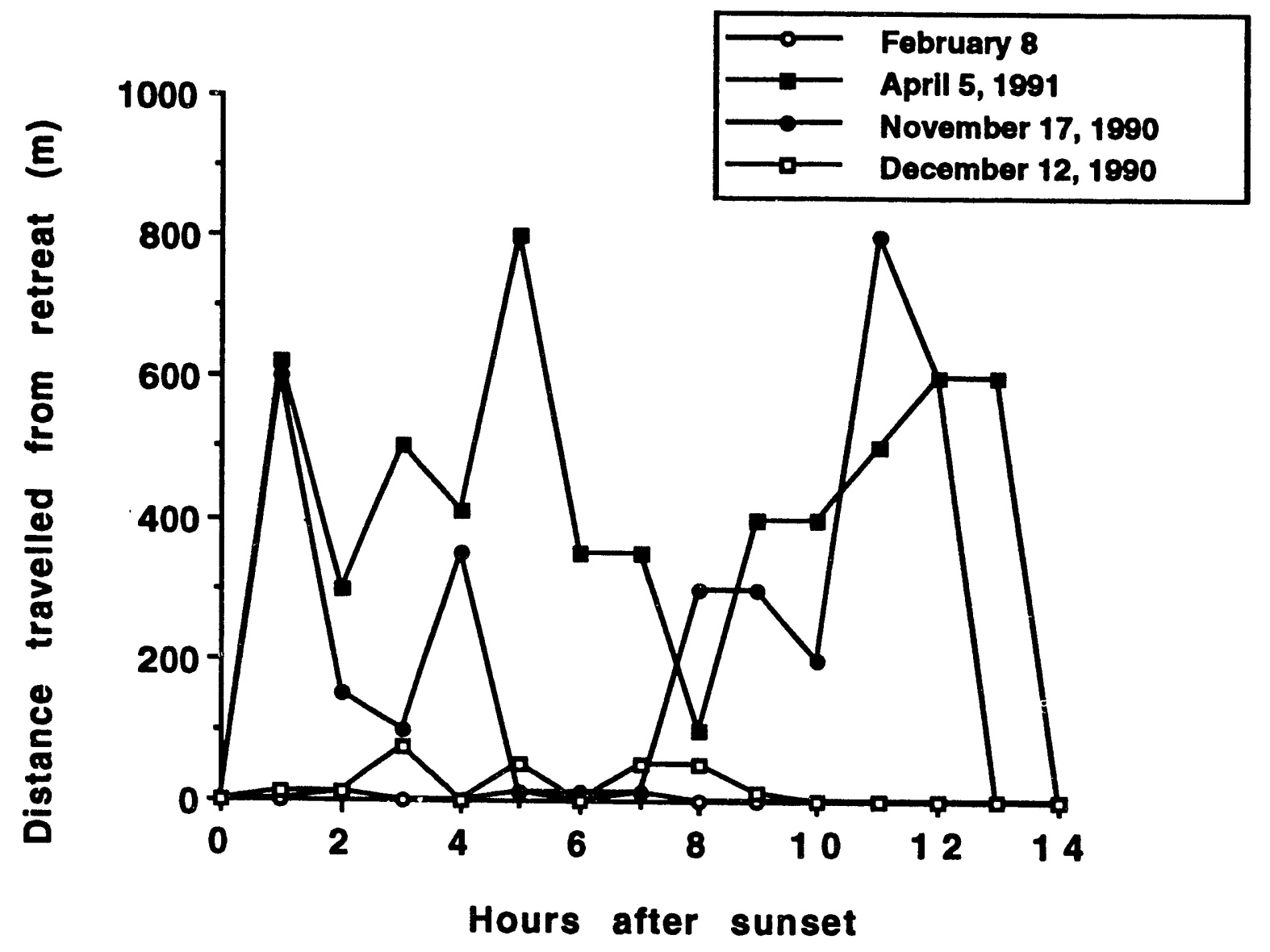

Fig. 7. Seasonal activity patterns of beaver \#930. Time out of the retreat site during freezeup (clear symbols) was limited to short ( $<10 \mathrm{~m})$ sorties to the feed bed. During ice-free periods (spring and autumn, filled symbols), beaver showed strongly bimodal activity patterns, returning to the retreat site in the middle of the nocturnal active period. 


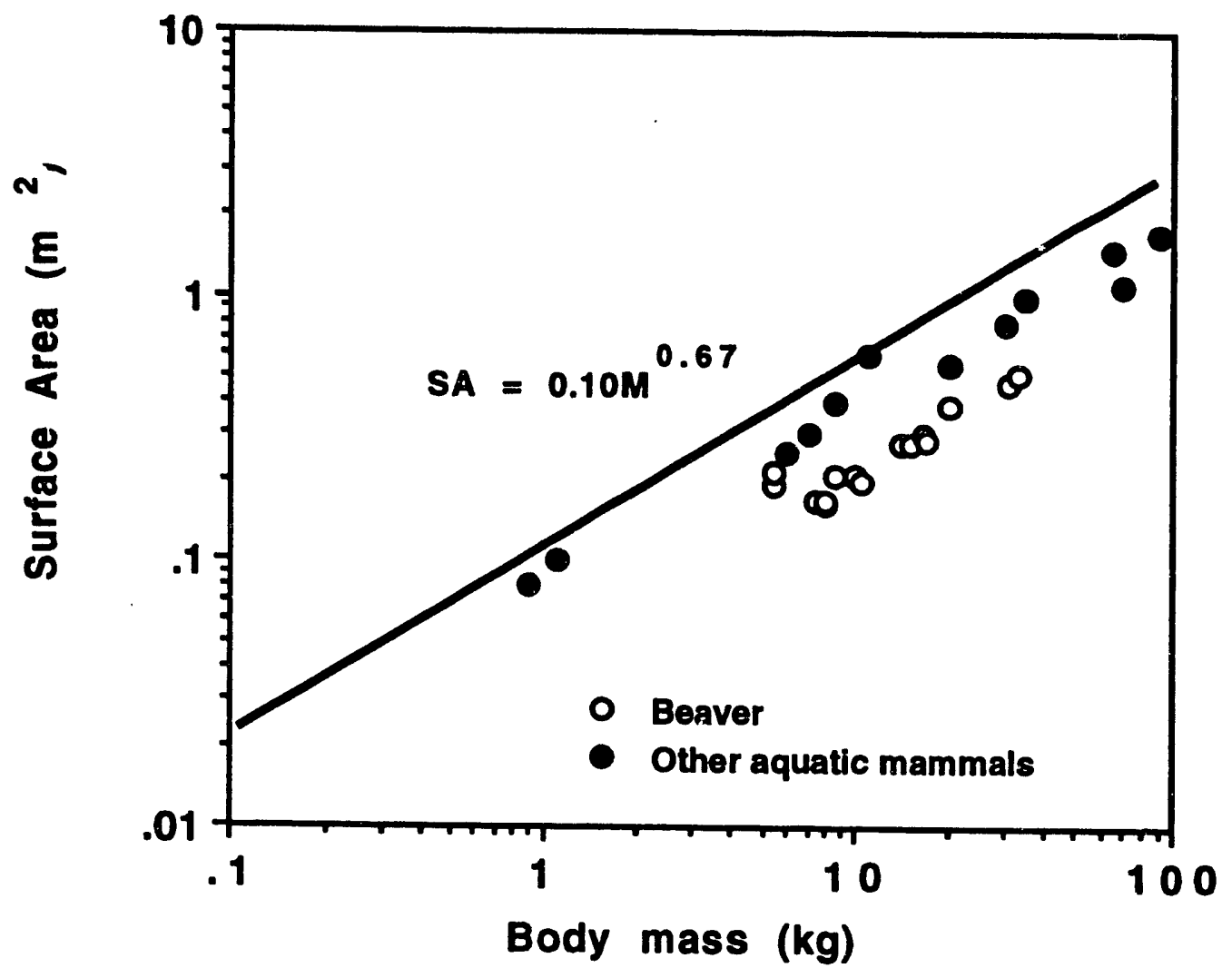

Fig. 8. Surface areas of aquatic mammals in relation to body size. 


\section{An evaluation of physiological properties and demographic characteristics of the six-lined racerunner lizard (Cnemidophorus sexlineatus) in southern Wisconsin. Joel Stein, graduate student}

Specific aims. The major goal of this project is to characterize the biophysical, life historical, and population ecology of Cnemidophorus sexlineatus in Wisconsin. The data I propose to collect, along with data from parallel studies of $C$. sexlineatus in other parts of the country, will be used to construct computer simulations to model the effects of climate change on individual energy budgets and population dynamics.

Background and significance. Many scenarios of climate change predict differences in global temperature and cloud cover that are similar to present day differences associated with elevation or latitude. For example, average monthly temperatures and active season lengths increase as one moves southward. By studying how animals are affected by environmental conditions along geographical gradients, one may predict how they will respond to changing climatic conditions. Lizards are ideal organisms for such studies because they are ectothermic, and their activity and energy budgets are sensitive to environmental variation. In particular, almost every aspect of lizard ecology is directly affected by temperature.

My work addresses the consequences of temperature for energetics, growth and reproduction in the six-lined racerunner Cnemidophorus sexlineatus. Although this species has been studied in much of its broad geographic range, little is known of its ecology in Wisconsin, the northern limit of its distribution. The short growing season in Wisconsin imposes limitations on activity time, which in turn is likely to affect other aspects of their ecology (e.g., growth, reproduction and mortality).

Northern and southern populations of $C$. sexlineatus experience different climates (Fig. 9), and show different activity patterns. Wisconsin lizards emerge from hibernation in mid-May, about two months later than lizards in the south. Immediately after emerging in the spring, lizards begin replenishing lost overwinter stores. Females begin to provision eggs with yolk, and males begin to produce sperm. At both sites, adults retreat into burrows in mid-August. The total adult activity season in Wisconsin is only three months long, which restricts their reproduction to one clutch per summer, versus two in South Carolina. The activity season for hatchlings is several months shorter in Wisconsin, delaying maturity and postponing first reproduction until year 2.

Populations in warm and cool environments are likely to have different patterns of energy acquisition and expenditure. Cooler spring temperatures in Wisconsin limit daily activity time, which may reduce their rate of resource assimilation relative to southern populations. In contrast, during the warmer summer months, activity time in Wisconsin is probably greater than in South 
Carolina, as the higher temperatures in the south curtail midday activity. Southern lizards may therefore experience higher metabolic rates during inactivity, resulting in greater energy expenditure relative to northern populations. Thus, both energy acquisition and energy expenditure are likely to be lower in Wisconsin, due to both the direct and indirect effecis of temperature.

I will examine physiological traits related to energy budgets and to organismal function at different temperatures. Traits to be examined include (1) locomotor performance and resource assimilation at lower body temperatures, (2) conservation of stored resources at higher inactive temperatures, and (3) resource allocation to growii and storage in hatchlings. Once sufficient quantitative data are available, I will then compare patterns of resource allocation (to growth, storage, and reproduction) with other populations farther south.

Progress report. This study was initiated in the summer of 1991 by establishing a marked population of 135 individuals in a sand prairie area near Spring Green, Wisconsin. Snout-vent length and mass were recorded for calculation of growth rates. Reproductive condition and amount of food in the gut were also noted. Periodically (approximately every three weeks) lizards were brought back to the lab where resting metabolic rate was measured, to construct a metabolic profile over the course of the active season.

Yearlings captured at the beginning of the summer were the same size as hatchlings captured at the end of the summer. This suggests that hatchlings devote most of their energy to storage (rather than growth) in their brief activity season. If they survive the first winter, they do most of their growing as yearlings, approximately doubling in size. Reproductive output was lower than expected, based on the limited literature on $C$. sexlineatus populations in Wisconsin. However, this may be due to weather variation between summers.

Experimental design and methods. A group of lizards collected at the Wisconsin site are being maintained in the lab. Over the course of the year, the following physiological traits will be measured:

1. Digestive performance. We will examine the temperature dependence of digestive efficiency and food passage time through the gut. The abundance of insects at the site suggests that energy acquisition is process limited rather than resource limited. This means that resource assimilation depends not on the quantity of food available, but on the rate and efficiency of digestive physiology, in combination with the temporal pattern of body temperatures.

2. Locomotor performance. We will examine the thermal dependence of sprint speed and endurance, by running the lizards on a high-speed treadmill at different body temperatures. This will show whether running performance is 
significantly impaired by the lower body temperatures early and late in the season.

3. Water loss. Evaporative water loss will be examined by placing the lizards in a wind tunnel and measuring the rate of change in mass. Water loss may be a limitation to activity under hot, dry conditions.

4. Field work. We will construct hollow-body copper models of $C$. sexlineatus for use next summer. When placed where the lizards perch and forage, these models will provide accurate estimates of the environmental temperatures experienced by lizards. This will allow us to quickly and accurately characterize thermal microclimates. This technique has been successfully used in the past by other members of this lab.

Next summer's field work will be the same as last's (recording snout-vent length, mass, reproductive condition, and amount of food in the gut), to refine patterns and clarify variation between years. We will concentrate on obtaining repeated measures on the same individuals from the previous year. Overwinter resource depletion and mortality will be examined. Field metabolic rates will be sstimated using doubly labeled water. This will test for differences in total meiabolic expenditure (active + inactive) between Wisconsin lizards and those further south. Subtracting out the resting metabolic rate (measured in the lab) from total metabolic expenditures (measured in the field) will allow an estimate of activity expenditure. If time permits, we will begin to investigate a critically underexplored stage in the lizard life history -- the egg stage. We will capture gravid females and induce them to lay eggs in the lab, and examine temperature and water conditions necessary for optimal egg development. 


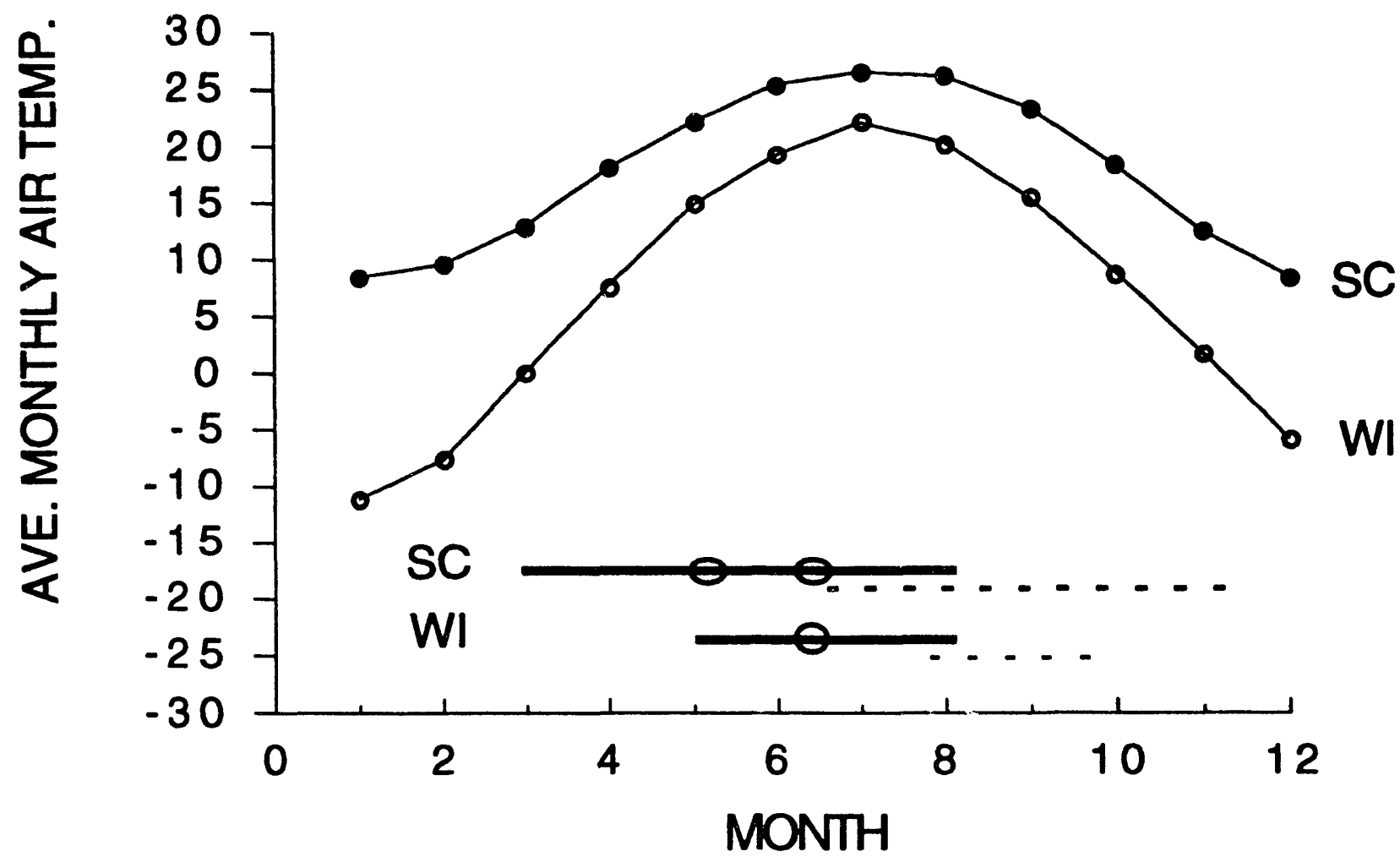

Fig. 9. Average monthly air temperatures $( \pm 1 S D$ ) are plotted versus month for Madison, Wisconsin, and Aiken, South Carolina. Beneath these curves, horizontal lines indicate the approximate dates of adult (solid lines) and hatchling (dotted lines) emergence (beginning of each line), initiation of brumation (end of each line), and oviposition (open circles) for Wisconsin and South Carolina populations. This illustrates the variation in environmental temperature and active season length between the two states. 


\section{E. An analysis of the effects of habitat fragmentation and climatic change on disjunct reptile populations. Charles Curtin, graduate student}

Specific Aims. I plan to study the ecology of three species: the six-lined racerunner lizard (Cnemidophorus sexlineatus), the ornate box turtle (Terrapene ornata ornata), and the western slender glass lizard (Ophisaurus attenuatus). My research addresses the question: Given present-day habitat limitations and predicted fluctuations in climate, can populations of these reptiles persist in Wisconsin?

This problem will be approached by tu . . . zns: (1) through determining both the spatial and physical limitations encountered by these species, the combined effects of climatic change and habitat fragmentation can be addressed to determine the probability of extinction of populations, and (2) by comparing population sizes as a function of local climate, I will evaluate potential changes in density following climatic shifts.

Background and Significance. While human actions through landscape fragmentation may decrease a species' range, habitat, or population size, it is ultimately stochastic events such as disease or shifts in climate which cause the demise of many species or populations. Most conservation studies have failed to address both the ecological and the physical limits facing species. This research will use approaches from both population and biophysical ecology to understand the ecological limits facing species and their populations.

Reptile species were selected because of their sensitivity to habitat fragmentation and the relative ease with which their biophysical ecology can be modeled. In Wisconsin the three species of interest, box turtles, glass lizards, and racerunner lizards, exist at the northern extreme of wide geographical ranges. They are dry prairie and savanna specialists with populations primarily relegated to disjunct patches of remnant native habitat (Vogt, 1981). Although these species exist in similar habitats, all three are segregated spatially with few of the populations overlapping. Though not globally threatened, both the box turtle and the glass lizard are listed as endangered in Wisconsin.

Climatic change can affect species by modifying the spatial or physiological limitations facing populations. The effects of spatial change (habitat fragmentation) on species or pop:slations has been well documented in the literature. Theories predicting a relationship between changes in spatial area and population size or species diversity have become the basis for much of the current understanding of conservation biology.

The impact of habitat fragmentation has been well documented for a variety of vertebrate populations. Ambuel and Temple (1983) recorded the effects of habitat fragmentation by demonstrating a decline in Wisconsin forest interior bird species. Temple and Carey (1988) examined some of the 
mechanisms responsible for the demise of these species. This study showed that impaired reproduction alone was enough to cause steep population declines and that without immigration from other regions the populations were likely to go locally extinct. Soule et al. (1988) have recorded the loss of birds from islands of chaparral habitat surrounded by urban sprawl in southern California. In Soule's studies, body size and population densities were found to be major indicators of the likelihood of species extinction. Bolger et al. (In review), in a continuation of Soule's work on chaparral canyons, have found that the size of the chaparral habitat, and the period of time in which the habitat has been isolated, are significant predictors of the number of native species found on the site.

Relatively less work has been done on reptile populations. Because of their low dispersal rates, reptiles should be highly sensitive to habitat fragmentation (Temple, pers. comm.). Initial work in California chaparral habitats indicates that reptiles are extremely sensitive to habitat fragmentation (Soule, pers. comm.).

Studies by Tinkle indicate that painted turtles in Michigan are significantly affected by edge effects with severe population decreases recorded (Tinkle et al., 1981). Wisconsin studies of box turtles indicate that fragmentation and edge effects are having a significant impact on these reptile populations. Temple (1987) found higher nest mortality in box turtle clutches located close to edges. The increasing fragmentation of their habitat makes it difficult or impossible for the turtles to lay eggs away from an edge. Doroff and Kieth (1988) noted high adult box turtle mortality near human habitation, apparently as a result of the fragmentation of their habitat.

Relatively les's is known about the effects of fragmentation on lizard populations. Richman et al. (1988) examined the extinction rates of isolated reptile species on islands. Human activities on isolated islands were found to increase extinction rates. Studies in Arizona are indicating significant edge effects on lizard populations in the Saguaro National Monument outside Tucson (Temple, pers. comm.).

Few researchers have addressed the effects of climatic change on reptile species. Work by Ellner and Karasov (MS) indicates significant changes in population densities and habitat requirements of Box Turtles across a latitudinal-climatic gradient. Grant and Porter (1991) established correlations between reproductive output and climatic variation. These studies support models indicating climate as a major variable affecting the viability of populations.

While it is well established that climatic change can greatly alter available habitat and population dynamics (Grant and Dunham, 1990; Porter, 1988), the effects of physical constraints and climatic change have been largely 
neglected in analysis of habitat fragmentation. Traditional ecological and population biological approaches often fall short of providing a sound understanding of the limitations facing species. Integrating the analysis of physical and spatial limitations can yield a more predictive and mechanistic understanding of the processes associated with habitat fragmentation and species extinction.

C. Progress Report/Preliminary Studies. Initial work on Wisconsin reptiles in the summer of 1990 sought to determine the size and viability of current populations of the racerunner lizards, box turtles, and glass lizards. I reviewed published data and found them to be inadequate for determining the viability of current populations (Curtin, 1990). An understanding of the physiological limits facing the reptile species and the effects of future climate shifts on both the species and their habitats was considered essential for estimating the viability of current populations.

Current research addresses several assumptions about Wisconsin reptile populations. Work cited earlier by Ambuel and Temple and Carey and Temple, on forest birds, and Doroff and Keith on box turtles, support the assumptions that (1) individual populations of Wisconsin reptiles are disjunct and therefore individual populations are isolated, and (2) the habitats inhabited by these animals are not large or diverse enough to support viable populations. To establish that box turtles, glass lizards, and racerunner populations are isolated, and that their habitats are small and not very heterogeneous, one needs to know the locations of populations and species habitat requirements.

At present a systematic inventory of all racerunner, glass lizard, and box turtle populations is being carried out in collaboration with Gary Casper of the Milwaukee Public Museum. Soil, vegetation, and habitat type are being examined to determine correlations between current locations of lizard populations and these physical factors. This information on the spatial limits of these reptile populations will determine the ecological bounds of species and populations as background for future biophysical studies.

\section{Experimental Design and Methods.}

(1) Given predicted climatic change can current populations of racerunner lizards, glass lizards, and box turtles persist? This work will contrast measures of the physiological constraints outlined in previous papers (Porter, 1989), with ecological and spatial parameters to estimate the likelihood of extinction of these species populations. If predicted climatic changes push Wisconsin reptile populations beyond the bounds of their physiological constraints, or if climatic changes eliminate or reduce these species' habitats, the populations will probably go extinct. 
Using climatic models (to be developed in this lab), shifts in plant community composition will be estimated (using published data), by comparing current plant communities with existing natural plant communities in environments comparable to those predicted in the climatic model. By contrasting current available habitat with predicted changes in plant community composition, available habitat will be estimated for four populations of each species.

Using doubly labeled water and biophysical models developed in this lab (Porter, 1989), growth and reproductive potential will be estimated for present populations and future populations under altered climatic conditions.

Through contrasting habitat availability with an understanding of biophysical limitations, the likelihood of extinction under present and future climatic conditions will be determined.

(2) Do changes in climate modify population densities, range. or habitat requirements? I will compare northern and southern populations of all three species. By comparing populations of a single species across a range of latitudes inferences can be drawn about how changes in climate can cause shifts in population densities and spatial requirements. These shifts in habitat requirements and density associated with regions of varying climate can yield predictions about how species and their habitats will respond to climatic change.

Using field measures of operational environmental temperature (using hollow copper models), by comparing measurements taken on Wisconsin populations with data published for southern populations, changes in potential daily activity time will be examined across latitudinal gradients. Changes in home range size and population density across latitudinal gradients will also be investigated. An understanding of these environmental, biophysical, and population changes can provide important insights into how these reptiles may respond to climatic change. Research on box turtles will rely primarily on existing published data. Work on racerunners and glass lizards will be based on a combination of Wisconsin field data to be collected by this lab and published data from southern populations.

\section{References clted}

Ambuel, B. and S. T. Temple. 1983. Area-dependent changes in the bird communities and vegetation of southern Wisconsin forests. Ecology. 64:1057-1068

Bolger, D. T., A. C. Alberts, R. M. Sauvajot, P. Potenza, C. McCalvin, D. Train, S. Mazzoni, and $M$. E. Soule. Effects of habitat fragmentation on native chaparral mammals: island and edge effects (MS).

Curtin, C. G. 1990. Effects of habitat fragmentation on four sand-prairie remnant reptiles. Unpublished report-Wisconsin Department of Natural Resources and The Nature Conservancy. 
Doroff, A. M. and L. B. Keith. 1988. Demography and ecology of an ornate box turtle (Terrapena ornata) population in south-central Wisconsin. M.A. Thesis, University of Wisconsin.

Ellner, L. R. and W. H. Karasov. Latitudinal variation in the thermal biology of ornate box turtles (MS).

Grant, B. W. and A. E. Dunham. 1990. Elevational covariation in environmental constraints and life histories of desert lizards Sceloporus merriami. Ecology 71: 1765-1776.

Grant, B. W. and W. P. Porter. 1991. Modeling global macroclimate constraints on ectotherm energy budgets. Physiological Zoology (In press).

Porter, W. P. 1989. New animal models and experiments for calculating growth potential at different elevations. Physiological Zoology 62: 286-313.

Richman, A. D., T. J. Case, T. D. Schwander. 1988. Natural and unnatural extinction rates of reptiles on islands. Am. Nat. 131: 611-630.

Soule, M. E. B. A. Bolger, A. C. Alberts, J. Wright, S. Sorice, and S. Hill. 1988.

Reconstructing dynamics of the rapid extinctions of chaparral-requiring birds in urban habitat islands. Biol. Conserv. 2: 75-95.

Temple, S. A. 1981. Applied island biogeography and the conservation of endangered island birds of the Indian Ocean. Biol. Conserv. 20: 147-161.

Temple, S. A. 1987. Predation on turtle nests increases near ecological edges. Copeia1987: 250-252.

Temple, S. A. 1988. Modeling the dynamics of forest-interior bird populations in a fragmented landscape. Conserv. Biol. 2: 305-312.

Tinkle, D. W., J. D. Congdon, and P. C. Rosen. 1981. Nesting frequency and success: implications for the demography of painted turtles. Ecology 62: 1426-1432.

Vogt, C.R. 1981. Natural history of amphibians and reptiles of Wisconsin. The Milwaukee Public Museum, Milwaukee, Wisconsin. 
V. Appendix: Additional publications by our lab group, supported by prior DOE awards

\section{A. Manuscripts submitted and in review}

Reynolds, P. S. Effects of body size and fur on heat loss of collared lemmings, Dicrostonyx groenlandicus. (submitted to Journal of Mammalogy)

Reynolds, P. S. Time-series analysis of body temperature patterns obtained by radiotelemetry. (submitted to Ecology)

French, J. B., Jr., and E. C. Burgess. Lyme disease in southern Wisconsin: Borrelia burgdorferi infection in Peromyscus leucopus and Ixodes dammini prevalence at the edge of its range. (submitted to Journal of Wildlife Diseases)

French, J. B., Jr., W. L. Schell, J. J. Kazmierczak, and J. P. Davis. 1992. Changes in density and distribution of Ixodes dammini (Acari: Ixodidae) in Wisconsin during the 1980's. (submitted to Journal of Medical Entomology)

\section{B. Publications}

Burgess, E. C., J. B. French, Jr., and A. Gendron-Fitzpatrick. 1990. Systemic disease in Peromyscus leucopus associated with Borrelia burgdorferi infection. American Journal of Tropical Medicine and Hygiene 42:254259.

Grant, B. W. 1990. Trade-offs in activity time and physiological performance for thermoregulating desert lizards, Sceloporus merriami. Ecology 71:23232333.

Lovvorn, J. R. 1990. Courtship and aggression in canvasbacks: influence of sex and pair-bonding. The Condor 92:369-378.

Munger, J. C., and W. H. Karasov. 1989. Sublethal parasites and host energy budgets: tapeworm infection in white-footed mice. Ecology 70:904-921.

Munger, J. C., W. H. Karasov, and D. Chang. 1989. Host genetics as a cause of overdispersion of parasites among hosts: how general a phenomenon? Journal of Parasitology 75:707-710. 

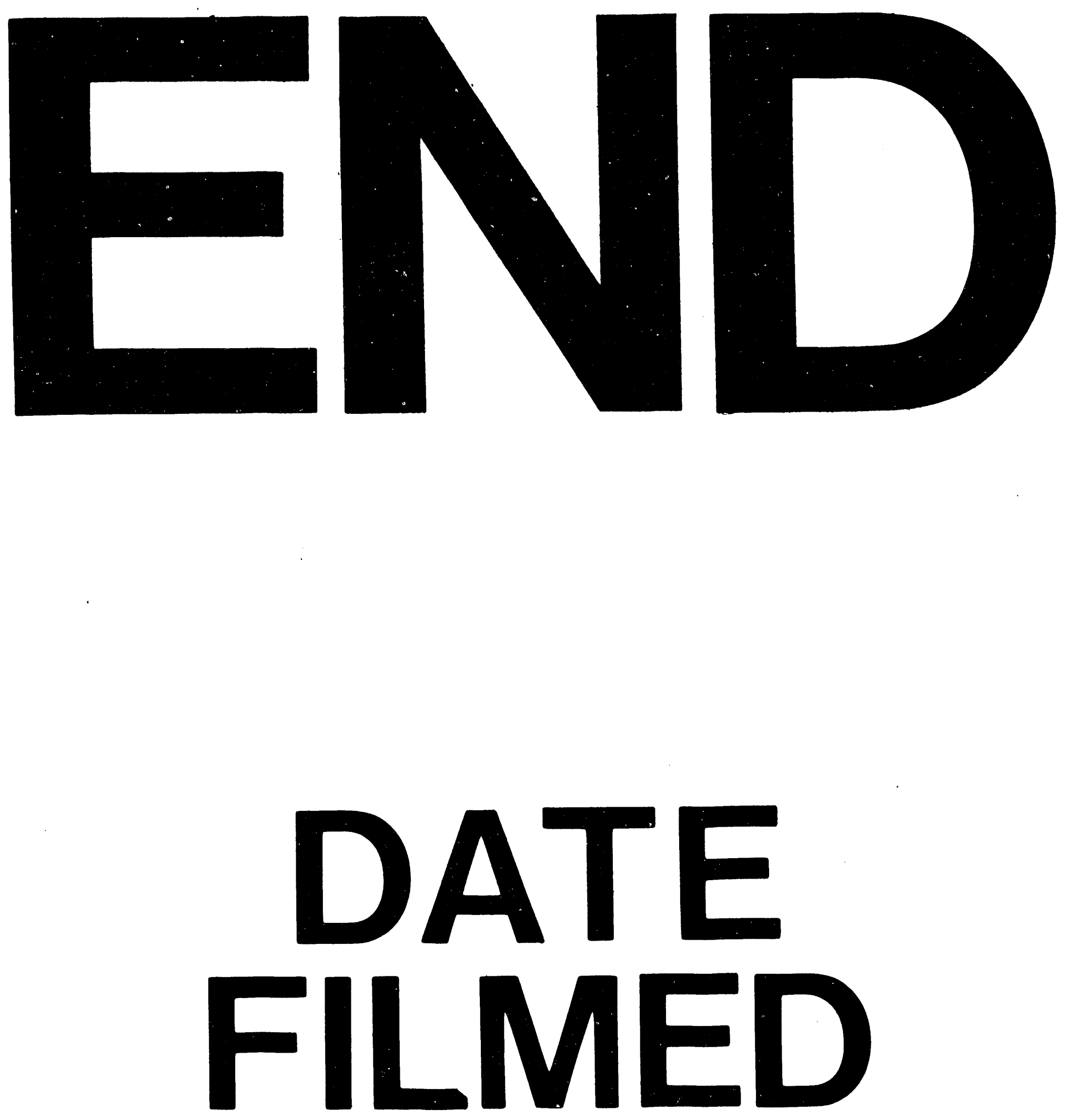

1

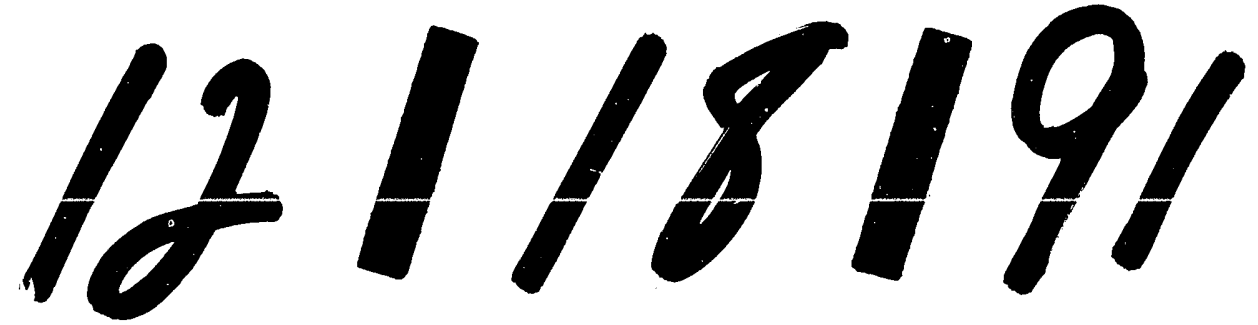


